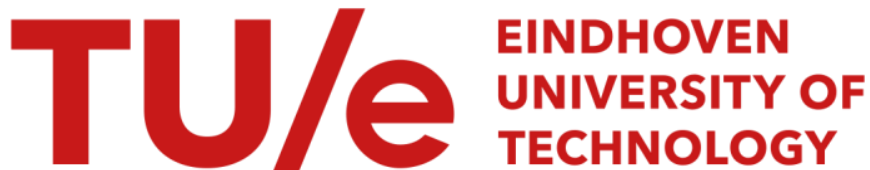

\section{Energy transfer in hybrid quantum dot light-emitting diodes}

Citation for published version (APA):

Chin, P. T. K., Hikmet, R. A. M., \& Janssen, R. A. J. (2008). Energy transfer in hybrid quantum dot light-emitting diodes. Journal of Applied Physics, 104(1), 013108-1/6. [013108]. https://doi.org/10.1063/1.2932149

DOI:

$10.1063 / 1.2932149$

Document status and date:

Published: 01/01/2008

\section{Document Version:}

Publisher's PDF, also known as Version of Record (includes final page, issue and volume numbers)

\section{Please check the document version of this publication:}

- A submitted manuscript is the version of the article upon submission and before peer-review. There can be important differences between the submitted version and the official published version of record. People interested in the research are advised to contact the author for the final version of the publication, or visit the $\mathrm{DOI}$ to the publisher's website.

- The final author version and the galley proof are versions of the publication after peer review.

- The final published version features the final layout of the paper including the volume, issue and page numbers.

Link to publication

\section{General rights}

Copyright and moral rights for the publications made accessible in the public portal are retained by the authors and/or other copyright owners and it is a condition of accessing publications that users recognise and abide by the legal requirements associated with these rights.

- Users may download and print one copy of any publication from the public portal for the purpose of private study or research.

- You may not further distribute the material or use it for any profit-making activity or commercial gain

- You may freely distribute the URL identifying the publication in the public portal.

If the publication is distributed under the terms of Article 25fa of the Dutch Copyright Act, indicated by the "Taverne" license above, please follow below link for the End User Agreement:

www.tue.nl/taverne

Take down policy

If you believe that this document breaches copyright please contact us at:

openaccess@tue.nl

providing details and we will investigate your claim. 


\title{
Energy transfer in hybrid quantum dot light-emitting diodes
}

\author{
Patrick T. K. Chin, ${ }^{1}$ Rifat A. M. Hikmet ${ }^{2}$ and René A. J. Janssen ${ }^{1, a)}$ \\ ${ }^{1}$ Molecular Materials and Nanosystems, Eindhoven University of Technology, P.O. Box 513, 5600 MB \\ Eindhoven, The Netherlands \\ ${ }^{2}$ Photonic Materials \& Devices, Philips Research Laboratories Eindhoven, High Tech Campus 4, 5656 AE \\ Eindhoven, The Netherlands
}

(Received 15 January 2008; accepted 24 March 2008; published online 7 July 2008)

\begin{abstract}
Energy transfer in a host-guest system consisting of a blue-emitting poly(2,7-spirofluorene) (PSF) donor and red-emitting CdSe/ZnS core shell quantum dots (QDs) as acceptor is investigated in solid films, using time-resolved optical spectroscopy, and in electroluminescent diodes. In the QD:PSF composite films, the Förster radius for energy transfer is found to be 4-6 nm. In electroluminescent devices lacking an electron transport layer, the electroluminescence (EL) spectrum of the QD:PSF polymer composite is similar to the photoluminescence (PL), giving evidence for energy transfer from PSF to the QDs. The addition of an electron transport layer between the emitting layer and the cathode results in a significant change in the EL spectrum and a considerable improved device performance, providing almost pure monochromatic emission at $630 \mathrm{~nm}$ with a luminance efficiency of $0.32 \mathrm{~cd} / \mathrm{A}$. The change in spectrum signifies that the electron transport layer changes the dominant pathway for QD emission from energy transfer from the polymer host to direct electron-hole recombination on the QDs. (C) 2008 American Institute of Physics. [DOI: $10.1063 / 1.2932149]$
\end{abstract}

\section{INTRODUCTION}

High quality colloidal core-shell semiconductor nanocrystals, or quantum dots (QDs), offer tunable narrow and intense photoemission as function of size in the visible range ${ }^{1-7}$ as a result of the spatial confinement of the excited charge carriers. ${ }^{8,9}$ This property can be used to make hybrid QD organic polymer light-emitting diodes (QD-LEDs) that combine the emitting properties of QDs with the flexibility in device construction of the organic and polymer materials. The use of QDs as a replacement of organic, polymer, or organometallic chromophores in LEDs has been demonstrated and is attracting increasing interest in an effort to obtain devices that combine the advantages of both systems for monochromatic visible and near infrared emission as well as for creating white light. ${ }^{10-41}$ Despite recent progress, device efficiencies of QD-LEDs still lag behind the more common organic and polymer LEDs.

Two types of QD-LED architectures can be discriminated. In the first device layout, a thin QD layer is sandwiched between a hole and electron injection layer such that excitons are formed directly in the QD layer. ${ }^{10-28}$ In the second layout, the active layer consists of a blend of QDs dispersed in a polymer ${ }^{29-39}$ or small molecule matrix. ${ }^{40,41}$ The QDs in this composite material serve as emissive traps for (migrating) excitons that are generated in the polymer matrix by charge carrier recombination. The use of such hybrid system where the QDs are embedded in a polymer matrix generally gives low luminance efficiency $(\sim 0.05 \mathrm{~cd} / \mathrm{A})$ for monochromatic devices but was recently reported to be $2.2 \mathrm{~cd} / \mathrm{A}$ for white-light-emitting devices. ${ }^{40}$ In these QD-

\footnotetext{
${ }^{a)}$ Author to whom correspondence should be addressed. Electronic mail: r.a.j.janssen@tue.nl.
}

LEDs, the QD electroluminescence (EL) originates either from recombination of injected charges in the host followed by Förster energy transfer ${ }^{33,35,42-44}$ to the QD, or by direct trapping and recombination of injected charge carriers on the QDs. In photoluminescence (PL), on the other hand, no (or few) free charge carriers are created in the host after photoexcitation and QD emission mainly stems from Förster energy transfer from the host, or from direct excitation of the QD. An in-depth study on energy transfer and carrier trapping differences in PL and EL in QD/polymer composite LEDs can contribute to the improvement of hybrid QD LEDs.

In this study, we use a conjugated blue-emitting $(450 \mathrm{~nm})$ poly (2,7-spirofluorene) (PSF) that possesses a fluorescence quantum yield of $40 \%$ as the host polymer matrix and energy donor together with red-emitting $(630 \mathrm{~nm})$ $\mathrm{CdSe} / \mathrm{ZnS}$ core shell QDs as energy acceptor. We show that the PL of the PSF polymer and the $\mathrm{CdSe} / \mathrm{ZnS}$ core-shell QDs in mixed films is governed by energy transfer from PSF to QDs. The mechanism can be described by Förster theory assuming a Förster radius of $4-6 \mathrm{~nm}$. The results obtained from photoexcitation are compared with electroluminescence studies of the same layers. In these QD-LEDs, energy transfer plays an important role when charge recombination is dominant in the polymer, but by introducing an electron transport layer, the QD emission can be significantly enhanced as a consequence of direct electron-hole recombination, leading to a red-light-emitting device with increased luminance efficiency.

\section{EXPERIMENT}

\section{A. Materials and sample preparation}

The PSF was obtained from Covion Organic Semiconductors $\mathrm{GmbH} .{ }^{45,46} \mathrm{CdSe} / \mathrm{ZnS}$ QDs were prepared according 
to literature procedures. ${ }^{2}$ Poly(3,4-ethylenedioxythiophene): poly(styrenesulfonate) (PEDOT:PSS), high resistance PEDOT 5411 Baytron was obtained from Bayer AG. TPBI [1,3,5-tris $(N$-phenylbenzimidazol-2-yl)benzene $]$ was obtained from Sensient Imaging Technologies Gmbh. All solvents were of analytical quality. The QDs were purified two times by dissolving a solid powder of singly purified CdSe/ZnS QDs in a certain amount of chloroform to obtain a $1 \%(w / v)$ dispersion and precipitating with an equal amount of methanol. The QDs were collected by centrifugation and dissolved in chloroform. Mixtures of the QD:PSF solutions in chloroform were deposited by spin coating using a BLE Delta 20 BM spin coater. For photoluminescence measurements, the emissive layer was spin coated on clean quartz substrates.

\section{B. Optical spectroscopy}

Steady state photoluminescence spectra were recorded using a PerkinElmer LS 50B spectrometer using $4.6 \mathrm{eV}$ as the excitation energy. UV-visible spectra were recorded using a PerkinElmer Lambda 900 spectrophotometer. Timeresolved fluorescence was measured using a streak camera setup (Chromex 250is polychromator 40 grooves $/ \mathrm{mm}$ grating, Hamamatsu 5677 Slow Speed Sweep Unit) in the dump mode with a temporal resolution of about 2 ps in the $2 \mathrm{~ns}$ detection window. The resolution in the detection window of $12 \mathrm{~ns}$ was $0.12 \mathrm{~ns}$. The excitation was carried out at $380 \mathrm{~nm}$ (Spectra Physics Millenia Xs pump laser, Spectra Physics Tsunami mode-locked Ti:sapphire laser, Spectra Physics 3980 frequency doubler and pulse selector). The streak camera spectra were corrected for the spectral response of the incoupling lenses, the polychromator, the streak tube, and the shading effects due to the deflection plate.

\section{Device preparation and characterization}

The QD-LEDs were fabricated under clean room conditions, using patterned indium tin oxide (ITO)/glass substrates with a $120 \mathrm{~nm}$ thick transparent ITO layer as the bottom electrode. The ITO/glass substrates are treated for $15 \mathrm{~min}$ with UV/ozone (UVP PR-100) before processing. A $\sim 100 \mathrm{~nm}$ PEDOT:PSS layer was deposited by spin coating and annealed at $180^{\circ} \mathrm{C}$ for $2 \mathrm{~min}$. Subsequently, the emissive QD:PSF mixture was deposited from chloroform solution by spin coating. The TPBI layer $(40 \mathrm{~nm})$ and $\mathrm{Ba}$ $(5 \mathrm{~nm}) / \mathrm{Al}(100 \mathrm{~nm})$ metal cathode were deposited by vacuum evaporation. The device area was $0.09 \mathrm{~cm}^{2}$. The QD-LEDs were characterized using a low-noise single channel dc power source, using a voltage/current source meter (Keithley 2400, Keithley Instruments). Light from the LED was measured using a photodiode and readout by an electrometer/high-resistance meter (Keithley 2400). The photodiode was calibrated with a luminance meter (Minolta LS110). The electroluminescence spectra were recorded using a fiber-coupled spectrograp/charge coupled device camera combination (Ocean Optics S2000). The emission was corrected for the wavelength dependence of the spectrometer.

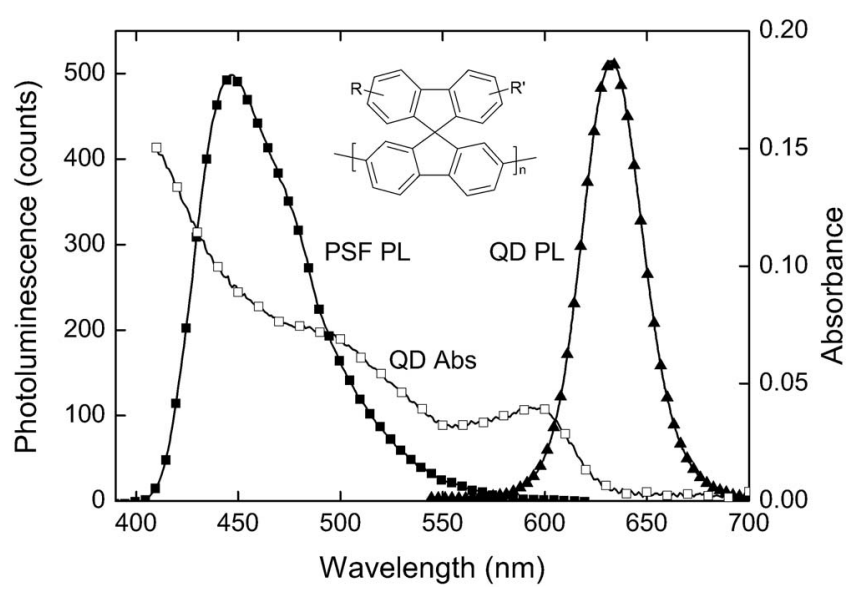

FIG. 1. Absorption (open squares) and PL (solid triangles) spectra of $\mathrm{CdSe} / \mathrm{ZnS}$ QDs compared to the PL spectrum of PSF (solid squares). All spectra were recorded for chloroform solutions at room temperature. The inset shows the molecular structure of PSF.

\section{RESULTS AND DISCUSSION}

\section{A. Energy transfer}

The absorption and PL spectra of CdSe/ZnS QDs in chloroform solution is shown in Fig. 1 and compared to the fluorescence spectrum of PSF. Figure 1 reveals that the QD absorption spectrum has a significant overlap with the fluorescence of PSF. This overlap is a requirement to enable efficient energy transfer from PSF to the QDs when they are mixed, ${ }^{47,48}$ and the spectral separation between PSF and QD PL emission allows detecting of both processes independently.

The efficiency of energy transfer from the PSF donor to the CdSe/ZnS QD acceptor can be expressed by the Förster radius $\left(R_{0}\right)$ at which half of the excited donor molecules decay by energy transfer and the other half by intrinsic radiative and nonradiative pathways. When energy transfer takes the form of interacting transition dipole moments on donor and acceptor, the Förster distance can be estimated from the spectral overlap $J$ (in $\mathrm{nm}^{4} / \mathrm{Mcm}$ ) of the photoluminescence $\left[F_{\mathrm{D}}(\lambda)\right]$ of the donor and the absorption $\left[\varepsilon_{A}(\lambda)\right]$ of the acceptor, via ${ }^{47,48}$

$$
R_{0}=0.211\left[\kappa^{2} n^{-4} \eta_{F}(\mathrm{D}) J\right]^{1 / 6} \text { (in Angstrom), }
$$

where $\kappa^{2}$ accounts for the relative orientation of the two transition dipole moments and is assumed to be equal to $2 / 3$ for random orientation of the dipole moments. ${ }^{49} \eta_{F}(\mathrm{D})$ is the luminescence quantum yield of the donor in the absence of acceptor, and $n$ is the refractive index of the solvent. From the spectra shown in Fig. 1, the Förster radius for PSF and $\mathrm{CdSe} / \mathrm{ZnS}$ was determined to be $\sim 6.2 \mathrm{~nm}$, in agreement with the values 5.4-5.8 nm (Ref. 42) and 6.7-7.0 nm (Ref. 44) that were recently reported for similar combinations of $\mathrm{CdSe} / \mathrm{ZnS}$ QDs and a wide band gap semiconducting polymer. Hence, in this range, energy transfer from PSF to $\mathrm{CdSe} / \mathrm{ZnS}$ QDs is rather efficient.

To investigate the energy transfer in films, the QDs were mixed with PSF in different mass ratios and deposited by spin coating from chloroform on quartz substrates. Figure 2(a) shows that the PL intensity of PSF in these mixed 

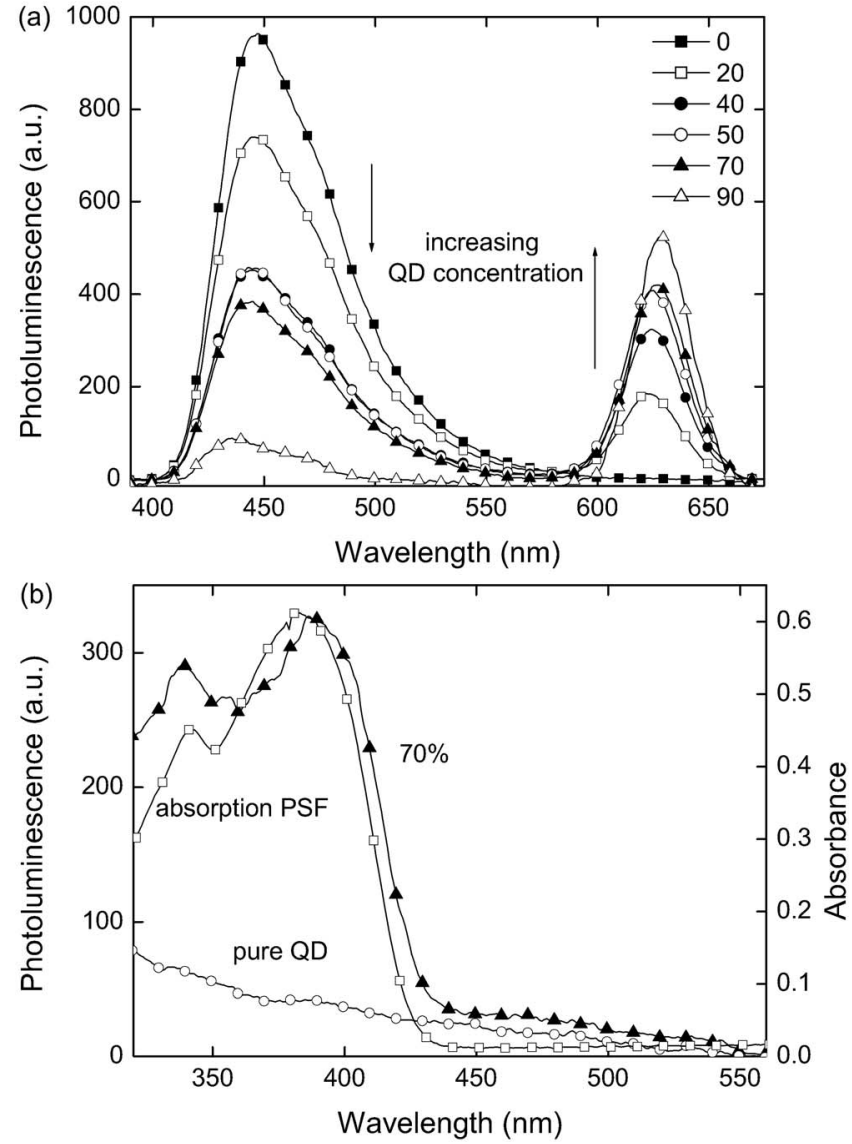

FIG. 2. (a) PL spectra of QD:PSF composite films for different wt \% of QDs (see inset) in the film. The PL intensity has been corrected for the absorbance at the excitation wavelength $(270 \mathrm{~nm})$. (b) PL excitation spectrum of a $70 \mathrm{wt} \%$ QD:PSF film recorded at $630 \mathrm{~nm}$ (solid triangles) together with the absorption spectrum of PSF (open squares) and the PL excitation spectrum of a pure QD film (open circles).

QD:PSF films significantly decreases with increasing QD concentration. At the same time, the PL intensity of the QDs increases, consistent with the expected energy transfer, but also possibly due to direct excitation. The PL excitation spectrum recorded at the maximum of the QD emission $(630 \mathrm{~nm})$ for the $70 \mathrm{wt} \%$ QD:PSF blend, however, shows the characteristic features of the absorption of PSF [Fig. 2(b)] and confirms that when exciting at $\sim 400 \mathrm{~nm}$ the QD emission results mainly from energy transfer from PSF to the QDs. The low intensity tail in the PL excitation above $\sim 450 \mathrm{~nm}$ [Fig. 2(b)] is due to absorption by the QDs.

For Förster energy transfer from a donor (PSF) to an acceptor (QD) that is randomly but rigidly distributed in three dimensions, the fluorescence intensity of the donor in donor-acceptor mixture $\left(I_{\mathrm{DA}}\right)$ can be described by ${ }^{48}$

$$
1-\frac{I_{\mathrm{DA}}}{I_{\mathrm{D}}}=\sqrt{\pi} \gamma e^{\gamma^{2}}[1-\operatorname{erf}(\gamma)],
$$

where $\gamma$ is given by

$$
\gamma=\frac{\sqrt{\pi}}{2} C_{a} \frac{4}{3} \pi R_{0}^{3}
$$

and $I_{\mathrm{D}}$ is the donor emission intensity in the absence of the acceptor and $C_{a}$ the concentration of QD acceptors

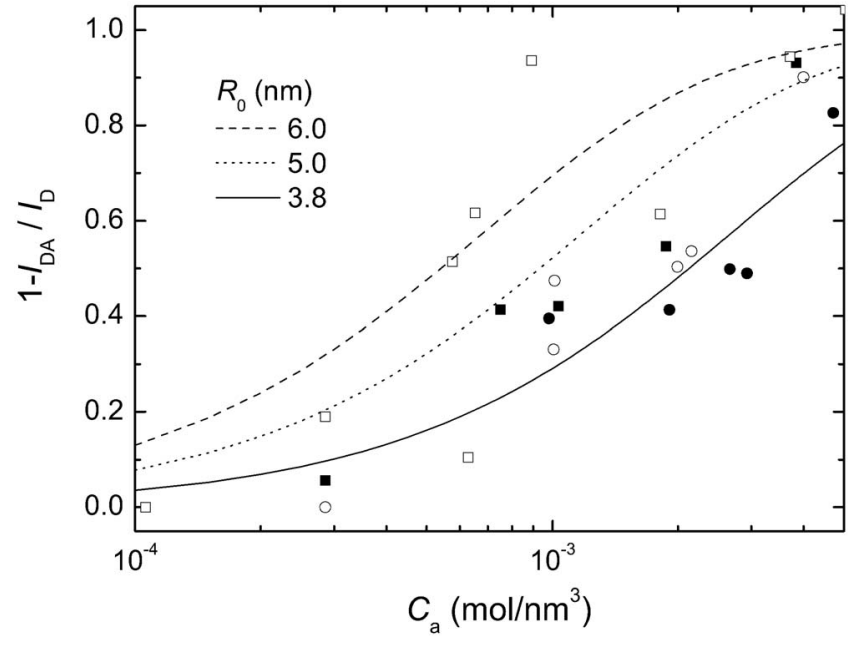

FIG. 3. Relative quenching $\left[1-\left(I_{\mathrm{DA}} / I_{\mathrm{D}}\right)\right]$ of the donor (PSF) fluorescence as function of the QD concentration $\left(C_{a}\right)$ in the film. The lines represent Eq. (2) for different Förster distances $R_{0}$. The experimental data are obtained for two different batches of QDs, each measured in two sets of experiments.

( $\left.\mathrm{mol} / \mathrm{nm}^{3}\right)$. To estimate $R_{0}$, different CdSe QDs batches were studied that had similar size, and compositions ( 2 or $3 \mathrm{ML}$ of $\mathrm{ZnS})$ and optical properties $\left(\lambda_{\mathrm{em}} \approx 630 \mathrm{~nm}\right)$. The relative quenching $\left[1-\left(I_{\mathrm{DA}} / I_{\mathrm{D}}\right)\right]$ of the donor (PSF) fluorescence as function of $C_{a}$ is plotted in Fig. 3 and compared to the calculated curves for different values for $R_{0}$. The experiments shown in Fig. 3 represent two different batches of QDs, each incorporated in two QD/polymer films, resulting in four sets represented by different markers. As can be seen, there is a considerable spread in the experimental data, due to inhomogeneous film formation, but the general trends shown in Fig. 3 are consistent with Eq. (2), when $R_{0}$ is in the range of 4-6 nm, in fair agreement with the $6.2 \mathrm{~nm}$ estimated from spectral overlap between donor emission and acceptor absorption.

Figure 4(a) shows the time-resolved photoluminescence intensity recorded at $460 \mathrm{~nm}$ of pristine PSF and of mixtures of QDs in PSF (20 and $50 \mathrm{wt} \%$ ). The fluorescence of PSF can be described by a biexponential decay with lifetimes $\tau_{1}$ $=95 \pm 1 \mathrm{ps}$ and $\tau_{2}=580 \pm 4 \mathrm{ps}$, with relative weights of about 2:1. As expected for energy transfer, the addition of QDs results in a decrease in emission lifetime of PSF $\left(\tau_{1}\right.$ $=83 \pm 1$ ps and $\tau_{2}=452 \pm 3$ ps with relative weight of 3:1 for 20 wt $\%$ QDs, and $\tau_{1}=73 \pm 1$ ps and $\tau_{2}=440 \pm 3$ with relative weight of 4:1 for $50 \mathrm{wt} \%$ QDs).

Figure 4(b) shows the QD time-resolved luminescence intensity monitored at $630 \mathrm{~nm}$ of the pure QDs and two QD:PSF blends. For the pure QDs the rise is monoexponential with a time constant of $\sim 3.7$ ps which is half of the FWHM of the machine response ( $8 \mathrm{ps}$ ). For the mixed films, we find a biexponential growth of the QD emission. The rise of the QD emission in QD:PSF blends clearly shows a contribution at longer time scales which we attribute to energy transfer from PSF to QD. For the $20 \mathrm{wt} \%$ blend, the QD emission rises with $\tau_{1}=6 \pm 1 \mathrm{ps}$ and $\tau_{2}=39 \pm 3 \mathrm{ps}$, while for the $50 \mathrm{wt} \%$ blend, the characteristic times are $\tau_{1}$ $=14 \pm 1 \mathrm{ps}$ and $\tau_{2}=232 \pm 15 \mathrm{ps}$. In both cases, we attribute 

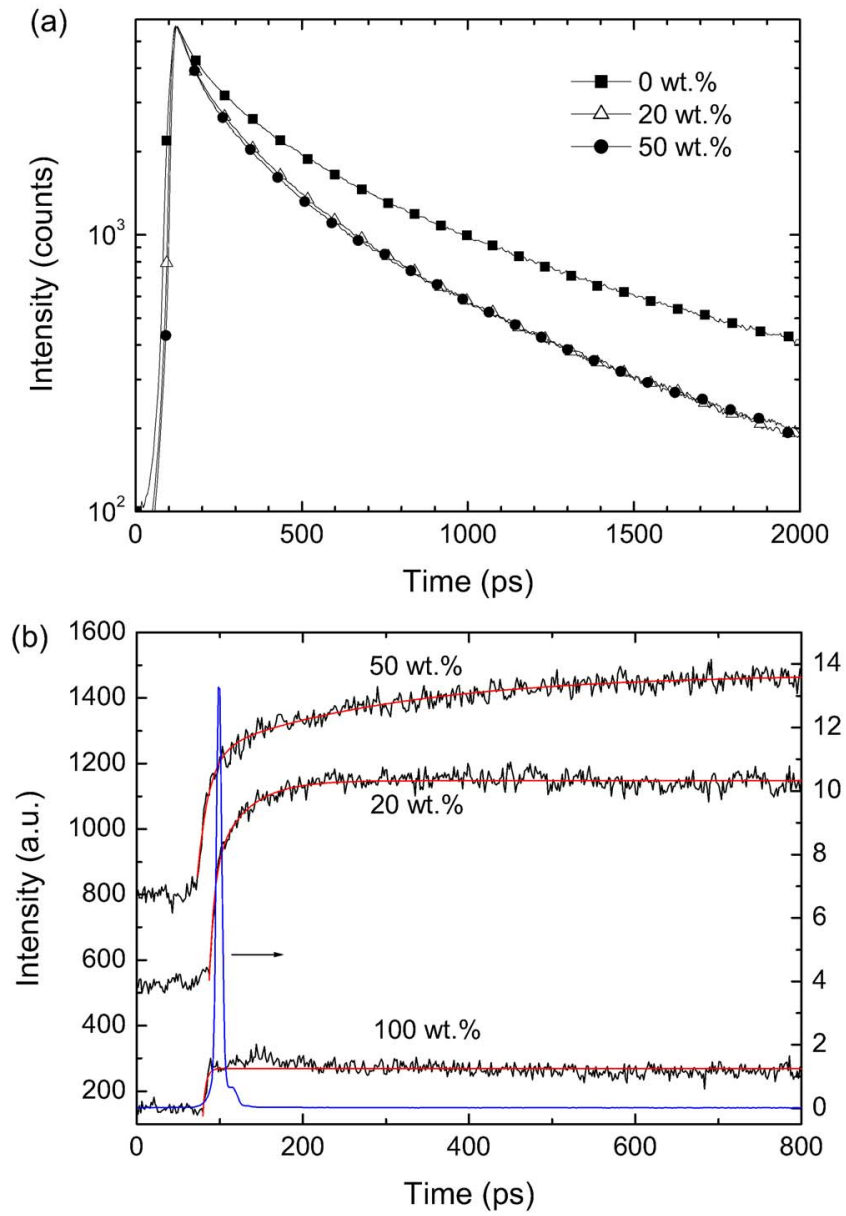

FIG. 4. (Color online) Time-resolved photoluminescence. (a) PSF emission at $460 \mathrm{~nm}$ of pure PSF (solid squares, $0 \mathrm{wt} \% \mathrm{QD}$ ) and of QD:PSF blends with 20 and $50 \mathrm{wt} \%$ QDs. (b) QD emission at $630 \mathrm{~nm}$ of pure QDs (100 wt \%) and QD:PSF blends 20 and 50 wt \% QDs. The red lines represent fits of a biexponential rise to the experimental data. The blue line represents the machine response of the excitation pulse. the short time to result mainly from direct QD excitation, while the long time is a typical signature of the energy transfer.

\section{B. Electroluminescence}

The EL was measured for composite QD:PSF films sandwiched between an ITO/PEDOT:PSS anode and a $\mathrm{Ba} / \mathrm{Al}$ cathode. The device architecture [Fig. 5(a)] contains an optional TPBI electron transport layer (ETL). The energy diagram of these QD-LEDs is shown in Fig. 5(b) and reveals that, in the active layer, holes will be confined to PSF while electrons may become trapped on the CdSe core.

In first approximation, the EL spectra of the QD:PSF composite film QD-LED devices without TPBI layer [Fig. 6(a)] are similar to the corresponding PL spectra (Fig. 2). The highest QD EL intensity is found for the layer containing $60 \mathrm{wt} \%$ QDs.

When the QD emission intensity in the blends is compared to that of PSF for the EL and PL experiments (Fig. 7), the increase in relative intensity with QD concentration is similar within experimental error. This similarity suggests that energy transfer from PSF to the QDs is responsible for the EL of the QDs and that direct electrical excitation $(e-h$ recombination) on the QDs is not predominant in these devices.

The performance of LEDs strongly depends on the balance of hole and electron currents. When the mobilities of holes and electrons differ significantly, an imbalance of charge carriers in the emitting layer will result. The excess of one type of charge carriers will lower the device performance because charge carriers may pass the active layer without recombination. Confinement of charge carriers to the emitting layer can be achieved by introducing electron or hole blocking layers (HBL). To confine holes in the lightemitting QD:PSF layer, we introduced a $40 \mathrm{~nm}$ thick thermally evaporated TPBI ETL/HBL between the QD:PSF layer

(a)

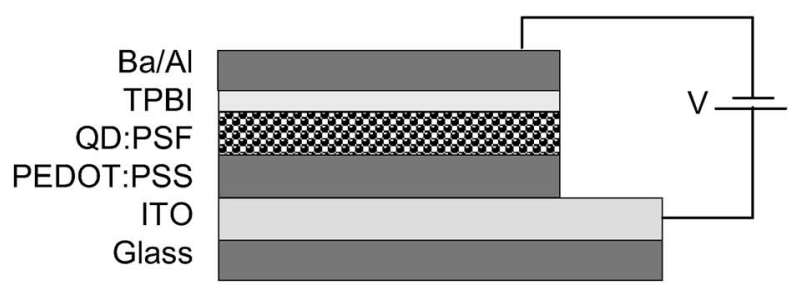

(b)

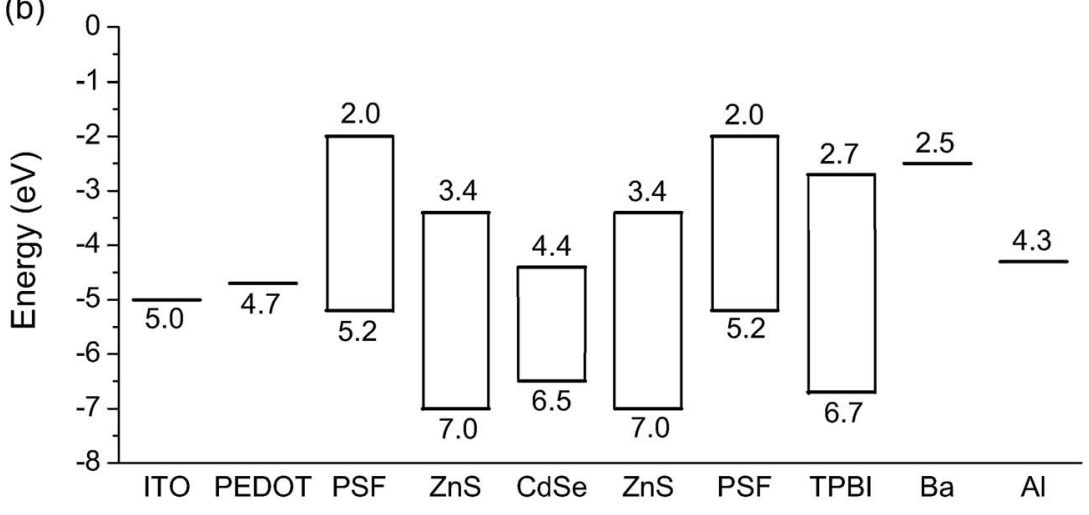

FIG. 5. (a) Schematic of the QD-LED device structure. The TPBI layer was not used in all devices (see text). (b) Energy levels of the various materials with respect to vacuum. 

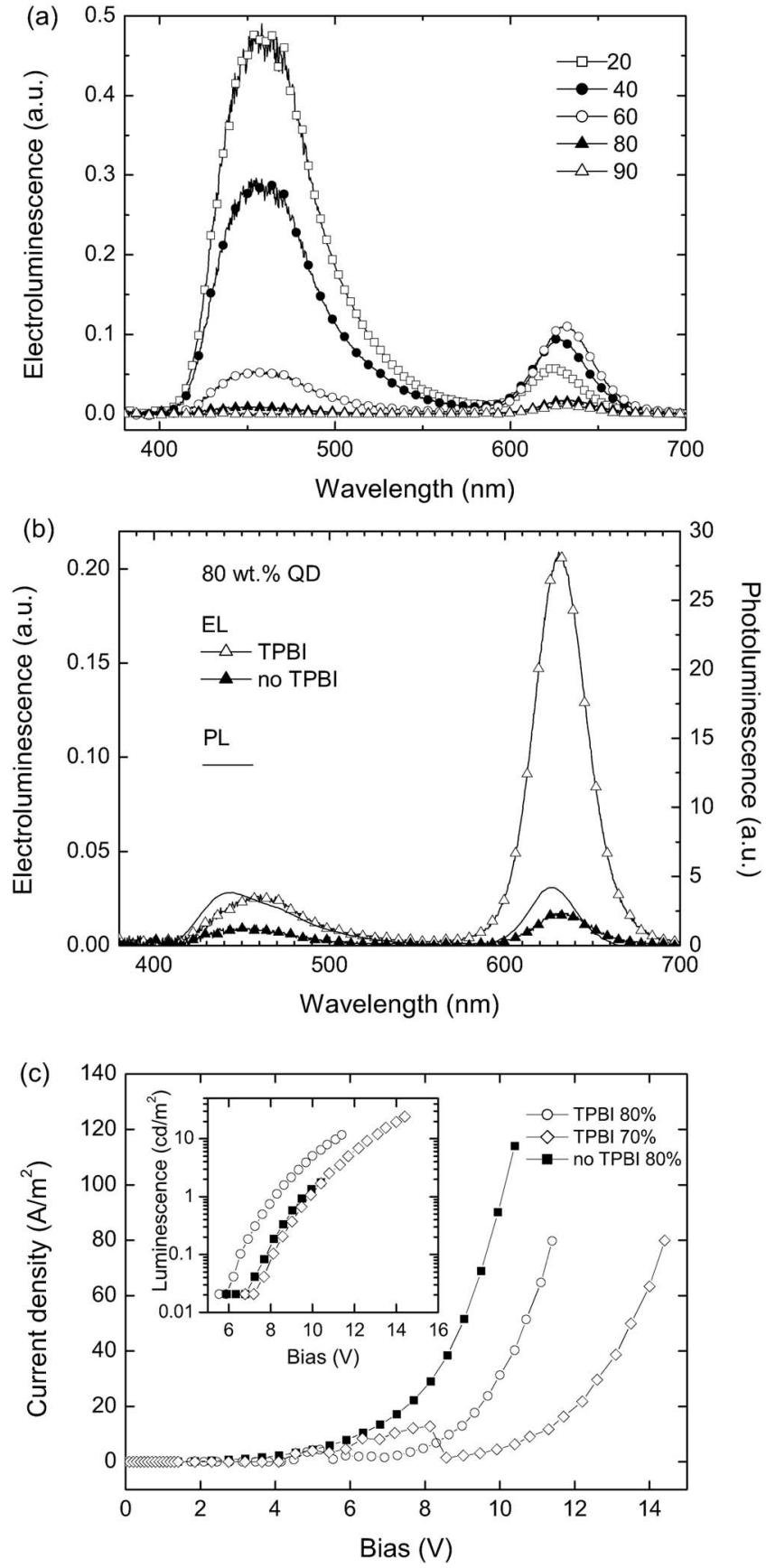

FIG. 6. (a) EL spectra of ITO/PEDOT:PSS/QD:PSF/Ba/Al QD-LEDs for different concentrations of QDs (in wt \%) measured at $J=55 \mathrm{~A} / \mathrm{m}^{2}$. (b) EL spectrum of an ITO/PDOT:PSS/QD (80 wt \%):PSF/TPBI/Ba/Al QD-LED (open triangles). The closed triangles show the corresponding EL spectrum without the TPBI ETL. The solid line represents the PL spectrum of the same film. (c) Current density and luminance of ITO/PEDOT:PSS/QD:PSF/ $\mathrm{Ba} / \mathrm{Al}$ LEDs vs the bias voltage without (solid symbols) and with (open symbols) a TPBI layer.

and the $\mathrm{Ba} / \mathrm{Al}$ cathode [Fig. 5(a)]. An additional advantage of an ETL/HBL is that it minimizes exciton quenching at the $\mathrm{Ba} / \mathrm{Al}$ cathode. Excitons close to the metal electrode often decay nonradiatively. Figure 6(b) shows the EL spectrum obtained for QD-LEDs with $80 \mathrm{wt} \%$ QDs in PSF (open markers). The $40 \mathrm{~nm}$ TPBI layer results in an increase in QD emission intensity by more than one order of magnitude compared to the device without TPBI (solid markers), while the polymer emission exhibits a threefold increase in EL

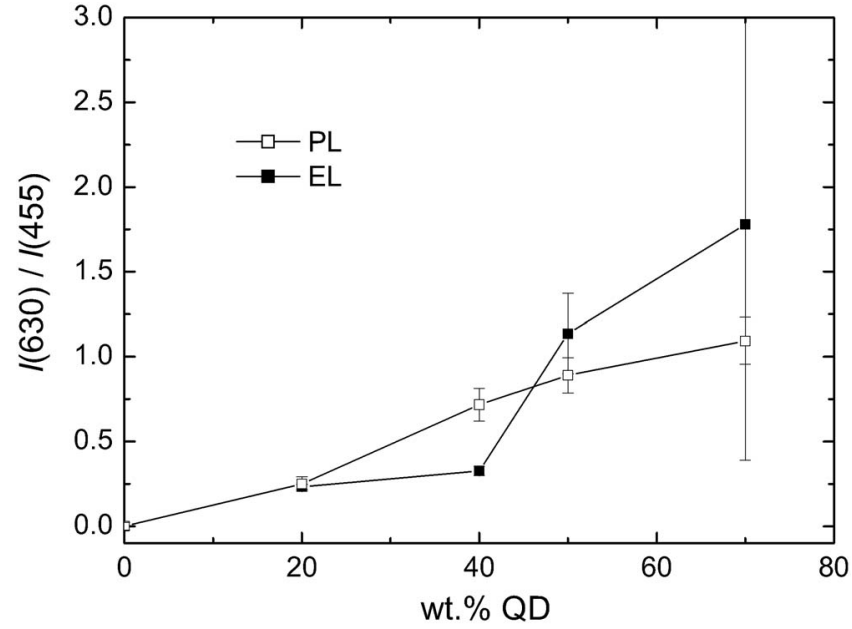

FIG. 7. Relative intensities of QD (630 nm) and PSF (455 nm) emission intensity from photoluminescence (open markers) and electroluminescence (closed markers) vs the concentration of QDs. At high QD wt \% the PSF emission becomes very small and the error in the ratio increases.

intensity. The larger increase in the QD emission compared to the PSF emission reveals that the TPBI layer causes charge recombination on the QDs to become the dominant pathway for exciting the QDs. The presence of polymer emission in the device with a TPBI layer is indicative of exciton formation PSF, which is even slightly increased by the TPBI layer as result of improved charge and exciton confinement. This shows that the QDs are not solely excited by charge trapping on the QDs but that energy transfer from PSF still occurs.

The current density and luminance of the devices with and without the TPBI layer are shown in Fig. 6(c). As can be seen, the current density of the QD-LEDs exhibits some sudden changes that are reminiscent of resistive switching phenomena, as observed in CdSe QD based organic memories. ${ }^{50,51}$ The $40 \mathrm{~nm}$ thick TPBI layer causes an increase in onset voltage for the current but not for light output. As a consequence, the QD-LED (80 wt \% QD in PSF) without TPBI layer has a maximum luminance efficiency of only $0.015 \mathrm{~cd} / \mathrm{A}$, which is increased to $0.16 \mathrm{~cd} / \mathrm{A}$ when using TPBI. The best device in terms of luminance efficiency [0.32 cd/A, Fig. 6(c)] was obtained for a QD-LED with a slightly lower concentration of QDs (70 wt \% in PSF) that included a TPBI ETL to enhance the QD emission compared to the PSF emission, similar to the $80 \mathrm{wt} \%$ blend shown in Figure 6(c).

\section{CONCLUSIONS}

Photoluminescence spectroscopy reveals that energy transfer in blends of core-shell CdSe/ZnS QDs and PSF as a conjugated polymer can be described with an average Förster radius between 4 and $6 \mathrm{~nm}$, in agreement with the estimate $(6.2 \mathrm{~nm})$ determined from the spectral overlap between donor emission and acceptor absorption. Energy transfer from PSF to the QDs was also evidenced from the PL excitation spectra and is reflected in the luminescence intensity dynamics where the QD emission continues to increase after the excitation pulse. The electroluminescence spectra of QD:PSF 
composite layers are similar to the photoluminescence spectra for devices that do not use a TPBI electron transport layer. The similarity suggests that under these conditions the QD emission arises mainly from Förster energy transfer from PSF and that direct electrical excitation ( $e-h$ recombination) on the QDs is not predominant. By using a TPBI electron transport layer, the electroluminescence spectrum was tunable to a more pure monochromatic QD emission. The considerably enhanced QD emission resulted in devices with luminance efficiency of 0.16 and $0.32 \mathrm{~cd} / \mathrm{A}$, for 80 and 70 wt \% QDs in PSF, respectively. The improved device performance together with the significantly increased QD emission suggests that TPBI enhances the emission that originates predominantly from direct electron-hole recombination in the QDs, by improved charge carrier trapping and by exciton confinement in the emissive layer. The results show that electroluminescence in QD composite LEDs does not mainly depend on energy transfer, but also on direct carrier recombination. ${ }^{35,40}$ In electroluminescence, carrier trapping becomes the main pathway for excitation in QDs when the charge carriers are effectively confined to the emissive layer.

\section{ACKNOWLEDGMENTS}

This work was funded by NanoNed and by the Interreg program OLED+.

${ }^{1}$ C. B. Murray, D. J. Norris, and M. G. Bawendi, J. Am. Chem. Soc. 115 , 8706 (1993).

${ }^{2}$ D. V. Talapin, A. L. Rogach, A. Kornowski, M. Haase, and H. Weller, Nano Lett. 1, 207 (2001)

${ }^{3}$ C. de Mello Donegá, S. G. Hickey, S. F. Wuister, D. Vanmaekelbergh, and A. Meijerink, J. Phys. Chem. B 107, 489 (2003).

${ }^{4}$ Z. A. Peng and X. Peng, J. Am. Chem. Soc. 123, 1389 (2001).

${ }^{5}$ B. O. Dabbousi, J. Rodriguez-Viejo, F. V. Mikulec, J. R. Heine, H. Mattoussi, R. Ober, K. F. Jensen, and M. G. Bawendi, J. Phys. Chem. B 101, 9463 (1997).

${ }^{6}$ I. Mekis, D. V. Talapin, A. Kornowski, M. Haase, and H. Weller, J. Phys. Chem. B 107, 7454 (2003).

${ }^{7}$ P. Reiss, J. Bleuse, and A. Pron, Nano Lett. 2, 781 (2002).

${ }^{8}$ A. P. Alivisatos, J. Phys. Chem. 100, 13226 (1996)

${ }^{9}$ A. L. Efros and M. Rosen, Annu. Rev. Mater. Sci. 30, 475 (2000).

${ }^{10}$ V. L. Colvin, M. C. Schlamp, and A. P. Alivisatos, Nature (London) 370 , 354 (1994).

${ }^{11}$ M. C. Schlamp, X. Peng, and A. P. Alivisatos, J. Appl. Phys. 82, 5837 (1997).

${ }^{12}$ H. Mattoussi, L. H. Radzilowski, B. O. Dabbousi, E. L. Thomas, M. G. Bawendi, and M. F. Rubner, J. Appl. Phys. 83, 7965 (1998).

${ }^{13}$ H. Mattoussi, L. H. Radzilowski, B. O. Dabbousi, D. E. Fogg, R. R Schrock, E. L. Thomas, M. F. Rubner, and M. G. Bawendi, J. Appl. Phys 86, 4390 (1999).

${ }^{14}$ S. Coe, W. K. Woo, M. G. Bawendi, and V. Bulović, Nature (London) 420, 800 (2002).

${ }^{15}$ S. Coe-Sullivan, W. K. Woo, J. S. Steckel, M. Bawendi, and V. Bulović, Org. Electron. 4, 123 (2003)

${ }^{16}$ R. A. M. Hikmet, D. V. Talapin, and H. Weller, J. Appl. Phys. 93, 3509 (2003).

${ }^{17}$ J. S. Steckel, S. Coe-Sullivan, V. Bulović, and M. G. Bawendi, Adv. Mater. (Weinheim, Ger.) 15, 1862 (2003).

${ }^{18}$ J. S. Steckel, J. P. Zimmer, S. Coe-Sullivan, N. E. Stott, V. Bulović, and M. G. Bawendi, Angew. Chem., Int. Ed. 43, 2154 (2004).
${ }^{19}$ S. Chaudhary, M. Ozkan, and W. C. W. Chan, Appl. Phys. Lett. 84, 2925 (2004).

${ }^{20}$ J. Zhao, J. Zhang, C. Jiang, J. Bohnenberger, T. Basché, and A. Mews, J. Appl. Phys. 96, 3206 (2004).

${ }^{21}$ R. A. M. Hikmet, P. T. K. Chin, D. V. Talapin, and H. Weller, Adv. Mater. (Weinheim, Ger.) 17, 1436 (2005).

${ }^{22}$ É. O'Conner, A. O'Riordan, R. Doyle, S. Moynihan, A. Cuddihy, and G. Redmond, Appl. Phys. Lett. 86, 201114 (2005).

${ }^{23}$ S. Coe-Sullivan, J. S. Steckel, W. K. Woo, M. G. Bawendi, and V. Bulović, Adv. Funct. Mater. 15, 1117 (2005).

${ }^{24}$ J. Zhao, J. A. Bardecker, A. M. Munro, M. S. Liu, Y. Niu, I.-K. Ding, J. Luo, B. Chen, A. K.-Y. Jen, and D. S. Ginger, Nano Lett. 6, 463 (2006).

${ }^{25}$ J. S. Steckel, P. Snee, S. Coe-Sullivan, J. P. Zimmer, J. E. Halpert, P. Anikeeva, L. A. Kim, V. Bulović, and M. G. Bawendi, Angew. Chem., Int. Ed. 45, 5796 (2006).

${ }^{26}$ Y.-H. Niu, A. M. Munro, Y.-J. Cheng, Y. Tian, M. S. Liu, J. Zhao, J. A. Bardecker, I. Jen-La Plante, D. S. Ginger, and A. K.-Y. Jen, Adv. Mater. (Weinheim, Ger.) 19, 3371 (2007)

${ }^{27}$ P. O. Anikeeva, J. E. Halpert, M. G. Bawendi, and V. Bulović, Nano Lett. 7, 2196 (2007)

${ }^{28}$ Q. Sun, Y. A. Wang, L. S. Li, D. Wang, T. Zhu, J. Xu, C. Yang, and Y. Li, Nat. Photonics 1, 717 (2007).

${ }^{29}$ B. O. Dabbousi, M. G. Bawendi, O. Onitsuka, and M. F. Rubner, Appl. Phys. Lett. 66, 1316 (1995).

${ }^{30}$ M. Gao, B. Richter, and S. Kirstein, Adv. Mater. (Weinheim, Ger.) 9, 802 (1997).

${ }^{31}$ M. Gao, C. Lesser, S. Kirstein, H. Möhwald, A. L. Rogach, and H. Weller, J. Appl. Phys. 87, 2297 (2000).

${ }^{32}$ N. Tessler, V. Medvedev, M. Kazes, S. Kan, and U. Banin, Science 295 , 1506 (2002).

${ }^{33}$ L. Bakueva, S. Musikhin, M. A. Hines, T. W. F. Chang, M. Tzolov, G. D. Scholes, and E. H. Sargent, Appl. Phys. Lett. 82, 2895 (2003).

${ }^{34}$ J. H. Park, J. Y. Kim, B. D. Chin, Y. C. Kim, J. K. Kim, and O. O. Park, Nanotechnology 15, 1217 (2004).

${ }^{35}$ Y. Li, A. Rizzo, M. Mazzeo, L. Carbone, L. Manna, R. Cingolani, and G. Gigli, J. Appl. Phys. 97, 113501 (2005).

${ }^{36}$ A. W. Tang, F. Teng, S. Xiong, Y. H. Gao, C. J. Liang, and Y. B. Hou, J. Photochem. Photobiol., A 192, 1 (2007).

${ }^{37}$ Y. Xuan, N. Zhao, D. Pan, X. Ji, Z. Wang, and D. Ma, Semicond. Sci. Technol. 22, 1021 (2007).

${ }^{38}$ C. Bertoni, D. Gallardo, S. Dunn, N. Gaponik, and A. Eychmüller, Appl. Phys. Lett. 90, 034107 (2007).

${ }^{39}$ Y. Xuan, D. Pan, N. Zhao, X. Ji, and D. Ma, Nanotechnology 17, 4966 (2006).

${ }^{40}$ Y. Li, A. Rizzo, R. Cingolani, and G. Gigli, Adv. Mater. (Weinheim, Ger.) 18, 2545 (2006).

${ }^{41}$ J. H. Ahn, C. Bertoni, S. Dunn, C. Wang, D. V. Talapin, N. Gaponik, A. Eychmüller, Y. Hua, M. R. Bryce, and M. C. Petty, Nanotechnology 18, 335202 (2007).

${ }^{42}$ A. Javier, C. S. Yun, and G. F. Strouse, Mater. Res. Soc. Symp. Proc. 776, Q2.1.1 (2003).

${ }^{43}$ M. Anni, L. Manna, R. Cingolani, D. Valerini, A. Cretí, and M. Lomascolo, Appl. Phys. Lett. 85, 4169 (2004).

${ }^{44}$ S. Kaufmann, T. Stöferle, N. Moll, R. F. Mahrt, U. Scherf, A. Tsami, D. V. Talapin, and C. B. Murray, Appl. Phys. Lett. 90, 071108 (2007).

${ }^{45}$ A. van Dijken, A. Perro, E. A. Meulenkamp, and K. Brunner, Org. Electron. 4, 131 (2003).

${ }^{46}$ H. Becker, A. Büsing, A. Falcou, S. Heun, E. Kluge, A. Parham, P. Stößel, H. Spreitzer, K. Treacher, and H. Vestweber, Proc. SPIE 4464, 49 (2001).

${ }^{47}$ J. R. Lakowicz, Principles of Fluorescence Spectroscopy, 2nd Ed. (Kluwer Academic, Dordrecht, 1999).

${ }^{48}$ B. Valeur, Molecular Fluorescence-An Introduction: Principles and Applications (VCH, Weinheim, 2000).

${ }^{49}$ G. D. Scholes and D. L. Andrews, Phys. Rev. B 72, 125331 (2005).

${ }^{50}$ B. C. Das, S. K. Batabyal, and A. J. Pal, Adv. Mater. (Weinheim, Ger.) 19, 4172 (2007).

${ }^{51}$ S. Sahu, S. K. Majee, and A. J. Pal, Appl. Phys. Lett. 91, 143108 (2007). 